\title{
Visibilidades da adoção: interrogando estratégias e práticas sociais
}

\author{
Visibility of child adoption: questions about social practices and strategies
}

Luciana Rodrigues ${ }^{[a]}$, Inês Hennigen ${ }^{[b]}$

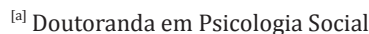
e Institucional pela Universidade Federal do Rio Grande do Sul (UFRGS), Porto Alegre, RS - Brasil, e-mail:

luciana_rodrig@yahoo.com.br

${ }^{[b]}$ Doutora em Psicologia, docente e pesquisadora da Universidade Federal do Rio Grande do Sul (UFRGS), Porto Alegre, RS - Brasil, e-mail: ineshennigen@gmail.com
}

Recebido: 06/03/2013 Received: 03/06/2013

Aprovado: $21 / 03 / 2013$ Approved: 03/21/2013

\section{Resumo}

Este trabalho propõe visibilizar aspectos históricos e movimentos recentes da política de adoção de nosso país a partir de articulações tecidas em uma pesquisa que, por meio de referenciais teórico-metodológicos relacionados aos estudos foucaultianos e ao campo do jornalismo, buscou problematizar o direito à convivência familiar e comunitária de crianças e adolescentes. Tecemos nossas discussões trazendo, pontualmente, algumas cenas da edição do programa Profissão Repórter, que colocou em pauta essa temática após a Nova Lei de Adoção ter completado um ano, e problematizamos a proposição de um Projeto de Lei (em tramitação na Câmara) que visa incentivar a prática da adoção de determinadas crianças e adolescentes a partir de um aumento na dedução do imposto de renda dos adotantes. Interrogamos que modos de pensar produzimos e que práticas sociais sobre a adoção desejamos promover ao atualizarmos a estratégia da adoção como "salvação" da garantia do referido direito e ao colocar um auxílio financeiro como respaldo à sua efetivação.

Palavras-chave: Adoção. Criança. Adolescente. Políticas públicas. Jornalismo.

\begin{abstract}
This paper has the purpose to expose historical aspects and recent movements of the Brazilian adoption policy. We started with articulations in a research that - through theoretical and methodological issues related to Foucaultian studies and journalism - wanted to problematize the right of children and teenagers of living in a family and a community. We made our discussions punctually using some scenes from a Brazilian television program called Profissão Repórter which talked about the New Adoption Bill (that has one year of existence). This study questions the proposition of the bill (in progress in Chamber of parliamentarians), which aims to encourage the practice of adoption of certain children and adolescents with an increase of the citizen's tax deduction. We question the ways of thinking we produce and which social practices we desire to promote when society update the strategy of adoption as a "salvation" to guarantee the right, putting, even, a financial assistance to support their effectiveness.
\end{abstract}

Keywords: Adoption. Child. Adolescent. Public policies. Journalism.

Psicol. Argum. 2014 jan./mar., 32(76), 93-103 


\section{Introducão}

Nos últimos anos, a proteção e defesa do direito à convivência familiar e comunitária de crianças e adolescentes vêm ganhando relevância nas políticas sociais brasileiras. Presente na Constituição Federal de 1988, este direito é reafirmado pelo Estatuto da Criança e do Adolescente (ECA), e tem ganhado novos documentos que visam efetivá-lo, como o Plano Nacional de Promoção, Proteção e Defesa do Direito de Crianças e Adolescentes à Convivência Familiar e Comunitária ${ }^{1}$ (que transversalizam o trabalho desenvolvido nos Serviços de Acolhimento) e a Lei $\mathrm{n}^{\circ}$ 12.010, chamada de Nova Lei de Adoção, que entrou em vigor em 3 de agosto de 2009.

0 presente texto parte das articulações tecidas na pesquisa de mestrado da primeira autora ${ }^{2}-$ que buscou problematizar, a partir de referenciais teórico-metodológicos relacionados aos estudos foucaultianos e ao campo do jornalismo, o direito à convivência familiar e comunitária de crianças e adolescentes - e tem o intuito de visibilizar os movimentos recentes da política de adoção de nosso país. Para tanto, apresentamos dados atuais e traçamos um breve percurso histórico sobre tal política, colocando em discussão alguns aspectos que se mostraram relevantes à luz da análise de uma edição do Programa Profissão Repórter (que foi ao ar em agosto de 2010 pela Rede Globo - o programa é exibido às terças-feiras, por volta das $23 \mathrm{~h}$ ) e que colocou em pauta a temática após a Nova Lei de Adoção ter completado um ano. Por fim, nos debruçamos sobre a proposição de um Projeto de Lei (em tramitação na Câmara) que visa incentivar a prática da adoção de determinadas crianças e adolescentes, a partir de um aumento na dedução do imposto de renda do(s) adotante(s).

Nossa escolha em utilizar cenas de reportagens jornalísticas ${ }^{3}$ pauta-se em perspectivas teóricas que concebem a materialidade midiática como uma rica

1 Ao longo do texto utilizaremos a sigla PNCFC para o referido Plano.

2 Ver Rodrigues, Luciana. (2012). Na cena jornalística, os Serviços de Acolhimento e a Adoção: incitamentos à vontade de família. Dissertação de Mestrado. Universidade Federal do Rio Grande do Sul. Instituto de Psicologia. Programa de Pós-Graduação.

3 Ao longo do texto optamos por utilizar o termo jornalismo (e suas variações), ao invés de telejornalismo, por possibilidade para pensarmos sobre os discursos que perpassam e compõe nosso cotidiano, e que se atualizam no exercício das práticas de cada sujeito. Como aponta Fischer (2002), a mídia "não apenas veicula, mas constrói discursos e produz significados, identidades e sujeitos" (p. 588). Assim sendo, entendemos que esse território constitui um modo de visibilidade em relação ao que é possível ser dito em uma determinada época; portanto, do que é possível ser considerado como verdade, que, conforme Foucault (2003), não está apenas ligada ao domínio da ciência, mas também aos sistemas de informação.

À mídia jornalística é, tradicionalmente, atribuída grande credibilidade, o que inscreve esse território midiático em um regime de verdade e visibilidade de verdades ditas "reais". Nesse sentido, o jornalismo se mostra como uma mídia "distinta" quanto à busca e à veiculação daquilo que "realmente" poderia ser considerar como uma verdade. Tal conformação do território jornalístico produz efeitos subjetivos importantes na medida em que "asseguraria" aquilo que os sujeitos poderiam qualificar como verdadeiro. Além disso, o jornalismo faz uso de recursos dramáticos, como a "novelização", termo que alguns autores da comunicação têm utilizado para discutir a apropriação jornalística do roteiro ficcional ${ }^{4}$ (Alencar, 2010), e que atualmente também se caracteriza pelo atravessamento do que tem sido chamado de infotainment - termo que traduz o embaralhamento das fronteiras entre informação e entretenimento (Gomes, 2010).

Essas diferentes estratégias utilizadas pela mídia jornalística em geral nos capturam pela sedução da vontade de verdade, pela construção de narrativas e imagens que, a exemplo do jornalismo investigativo, buscam a verdade lá onde realmente estaria: na rua, na casa, no corpo, na dor, na alegria de cada sujeito. Mostram, dessa maneira, histórias que não são de qualquer vida, mas sim de uma vida dita "real" - embora essas narrativas, como as ficcionais, sejam produzidas e nos convocam a ver determinadas coisas. Ao estarem relacionadas aos fatos cotidianos,

entender que o primeiro se refere a uma linguagem específica que abrange o modo de construção de um telejornal.

${ }^{4}$ A autora chama a atenção para não se confundir a questão da novelização do telejornalismo com alguma forma de manipulação sobre os telespectadores, pois entende que a veracidade dos fatos é permanentemente esperada pelo público e não estaria comprometida por tal processo. 
acabam ofertando ou rechaçando determinadas posições de sujeito e modos de viver como mais ou menos aceitáveis. E, nesse jogo, contribuem para a naturalização de certos modos de olhar e compreender o mundo.

Para tecer nossa análise, seguimos a concepção de discurso de Foucault (2004a), entendendo-o como uma prática que forja objetos. 0 filósofo nos convida a problematizar os discursos para que, assim, possamos visualizar como as coisas estão dispostas, como foram montadas. Tal convite propõe que interroguemos as condições de verdade para pensarmos sobre outras possibilidades e formas de habitar o mundo. Trilhar este caminho não significa que procuramos por algo oculto atrás dos discursos (já que não há nada por trás das cortinas, toda a realidade está manifesta), mas sim que visamos trazer à luz, dar visibilidade aos ditos e não ditos, ao que está sendo enunciado nos discursos. Sustentada nas concepções de Foucault (2004a), operamos com a descrição das coisas ditas, uma análise histórica que não está interessada em interpretações, mas na compreensão do modo como as coisas são passíveis de existência.

Assim, recortamos do referido programa cenas que, ao apresentarem leis e dados relacionados à garantia do direito à convivência familiar e comunitária de crianças e adolescentes, partem de movimentações políticas que colocam a família como prioridade das intervenções socioassistenciais. São tais movimentações que criam condições para que temáticas como a adoção ganhe visibilidade na mídia brasileira - que, por sua vez, dispersa pelo tecido social informações sobre a própria política.

Antes de prosseguir, ressaltamos que trabalhar com cenas e discursos veiculados em reportagens não exclui o caráter de produção dessas narrativas. Mesmo as histórias visibilizadas como "reais" e "verdadeiras" são produções que nos convocam a ver determinadas coisas (e de certos pontos de vista), pois há uma edição, um recorte na construção de narrativas e imagens que, por sua vez, contribui para a naturalização de nosso modo de olhar, e nos convida também a assumir determinados modos de ser e compreender o mundo à nossa volta. E é a um determinado modo de ver certas crianças e adolescentes que lançaremos luz ao longo desse trabalho, para que possamos, assim, pensar não a respeito do que é ou não é real, mas o quanto essas produções que nos interpelam estão implicadas na produção de nosso pensar sobre o presente e a vida.

\section{Para uma infância em família: o governo da adoção}

Conforme aponta o Levantamento Nacional de Abrigos para Crianças e Adolescentes, realizado pelo Instituto de Pesquisa Econômica Aplicada (IPEA) em 2003, as causas que levam ao abrigamento de crianças e adolescentes estão relacionadas ao abandono pelos pais ou responsáveis $(18,9 \%)$, à violência doméstica $(11,7 \%)$, a pais ou responsáveis que são dependentes químicos $(11,4 \%)$, à vivência na rua (7\%), à orfandade $(5,2 \%)$, à pobreza $(24,2 \%)$ e a outros motivos $(21,6 \%)$ (Brasil, 2006). Figurando como o índice de maior relevância, a pobreza não deveria ser motivo para uma medida de proteção - no caso, o abrigamento - ser acionada, pois "a falta ou a carência de recursos materiais não constitui motivo suficiente para a perda ou a suspensão do poder familiar" (Brasil, 1990, art. 23).

Há um número bastante elevado de crianças e adolescentes em acolhimento institucional no país. Segundo dados do Levantamento Nacional (relativo apenas aos abrigos ligados ao governo federal) são cerca de 20 mil crianças e adolescentes. Entre aqueles que estão disponíveis para o processo de adoção, quando o poder familiar já foi destituído, a maioria é de meninos, afrodescendentes, com idade superior a 7 anos. Em uma das reportagens apresentadas pelo programa Profissão Repórter sobre adoção, somos informados que $96 \%$ das pessoas que aguardam na fila de espera da adoção desejam crianças de até 3 anos de idade, branca e do sexo feminino. Aspecto que é corroborado pela reposta emblemática de Cátia - mulher que é entrevistada pela repórter do programa sobre o porquê de seus três anos de espera na fila de adoção. Ela diz que é "muito em função do perfil [...] A gente espera um bebê [...] até um ano, branco, né, e a maioria que tem é de outras etnias [...] Uma criança mais velha vem com algumas histórias e [de] algumas histórias eu não me sinto preparada pra dar conta". No final do programa, ao entrevistar uma mãe que recentemente havia recebido seu filho (um bebê afrodescendente), a repórter pergunta por que ela achava que a adoção tinha acontecido tão rápido. A resposta foi "as pessoas exigem demais para adotar". 0 que não surpreende quando $61,3 \%$ daqueles que vivem em abrigos têm idade entre 7 e 15 anos; 58,5\% são meninos e 63\% afrodescendentes (Brasil, 2006).

Propondo mudanças nesse contexto (para assegurar o direito à convivência familiar e

Psicol. Argum. 2013 jul./set., 32(76), 93-103 
comunitária), a Nova Lei de Adoção trouxe entre suas principais mudanças: a revisão do processo judicial, a cada seis meses, para avaliação da situação de cada criança e adolescente em acolhimento institucional; a fixação de um período máximo de dois anos de permanência em instituições; a preferência ao acolhimento em família em detrimento ao acolhimento em abrigo; a diminuição na idade mínima para ser mãe/pai adotivo (de 21 para 18 anos); o apoio à gestante que manifestar interesse em entregar o bebê para adoção; a criação de um cadastro para adotantes e outro para adotados; e o direito do adotado de conhecer sua origem biológica, com acesso irrestrito ao processo de adoção a partir dos 18 anos de idade.

Estratégias que pretendem agilizar o processo de adoção, as quais podemos pensar a partir da concepção de governamento de Michel Foucault, pela qual se busca conduzir a conduta dos sujeitos a determinado modo de governar a si e os outros; nesse caso, visa atingir determinado fim: reinserir a criança e o adolescente em uma nova família com maior rapidez. Foucault (2004b) nos mostra como esse modo de governar, essa nova arte de governar que se diferenciou do poder soberano, emergiu a partir do surgimento da população como um campo possível de intervenção, caracterizando o que o filósofo chamou de "governamentalidade": um conjunto que se constitui tanto pelas instituições como pelas análises, cálculos e táticas que, por sua vez, possibilitam exercer sobre a população uma forma específica de poder que faz uso do saber da economia política e dos dispositivos de segurança (Foucault, 2004b).

Com essa nova arte de governar o que se busca é uma maneira correta de dispor as coisas para melhor conduzi-las, não necessariamente ao bem comum, mas a um objetivo adequado a cada uma das coisas a governar (Foucault, 2004b). Um modo de governar que se distanciou do poder soberano e só tinha finalidade em si mesmo. 0 governo agora tem finalidade nas coisas que dirige; trata-se de uma arte de governar que irá lançar mão da economia e de um exercício de poder que assume uma forma econômica para conduzi-las (Foucault, 2009). Com o surgimento da população como um campo de intervenção, da economia como um domínio específico de realidade e da economia política como técnica de intervenção do governo se estabelece uma tríade formada por governo, população e economia política, que permanece articulada até os dias de hoje e caracteriza o processo pelo qual "o Estado administrativo, viu-se pouco a pouco 'governamentalizado"' (p. 144).

A partir desse contexto, através de um saber construído pelo uso da estatística, será possível mostrar as regularidades próprias da população, o que possibilita ver sua irredutibilidade em relação ao âmbito familiar. Deste modo, de modelo de gestão, a família, no interior da população, passou a ser instrumento de intervenção do governo, assumindo uma função política e constituindo um segmento privilegiado "porque, quando se quiser obter alguma coisa da população quanto ao comportamento sexual, quanto à demografia, ao número de filhos, quanto ao consumo, é pela família que se terá efetivamente de passar" (Foucault, 2009 , p. 139). E a meta final do governo e suas finalidades específicas serão melhorar as condições de vida, saúde e riqueza da população, seja mediante campanhas direitas ou "por meio de técnicas que vão permitir, por exemplo, estimular, sem que as pessoas percebam muito, a taxa de natalidade, ou dirigindo nesta ou naquela região, para determinada atividade, os fluxos de população (Foucault, 2009, p. 140).

No Brasil, no que se refere ao governo da população de crianças e adolescentes, a família é requisitada como instrumento passível de intervenção a determinadas finalidades, pois historicamente - e mais ainda a partir da Doutrina de Proteção Integral de crianças e adolescentes - vemos a família ganhar prioridade absoluta em nossas políticas sociais (Cruz, 2009). Basta atentarmos para o grande número de políticas e programas que buscam incentivar determinadas condutas familiares - como o Programa Bolsa Família ${ }^{5}$ - com a justificativa de uma promoção, seja em relação à saúde, à educação e à proteção integral de crianças e adolescentes. Em relação ao direito à convivência familiar e comunitária não é diferente. Como nos fala Fonseca (2009), embora a ideia de convivência familiar não seja nova ao ECA, o novo milênio trouxe mudanças para as políticas sociais direcionadas

\footnotetext{
${ }^{5}$ Programa de transferência de renda, com algumas condicionalidades, que beneficia as famílias em situação de pobreza e extrema pobreza.
} 
à população de jovens caracterizados em situação de risco.

Hoje, depois de ter vivido a esperança na institucionalização nos anos de 1970 e 1980, e na adoção durante os anos de 1980 e 1990, a maioria de organizações está concentrando seus esforços na convivência familiar. [...] Enquanto, durante os anos 1990, havia muita atenção centrada na família adotiva, hoje as discussões giram em torno da manutenção de crianças nas suas famílias de origem ou [...] eventualmente [...]da promoção de famílias de acolhimento (Fonseca, 2009, pp. 285-286).

Articulada à estratégia que tenta governar a permanência da criança e do adolescente em família, encontra-se a política de Assistência Social, regulamentada pela Lei Orgânica da Assistência Social Loas $^{6}$ (Brasil, 1993) que, com o objetivo de proteger a família, estabelece ações que auxiliam a assegurar e defender o direito à convivência familiar e comunitária de crianças e adolescentes.

Nesse sentido, preocupada com as questões voltadas à família, em 2002, a Secretaria de Assistência Social promoveu o Colóquio Técnico sobre Abrigos, espaço no qual instituições não governamentais e governamentais apontaram a falta de informação sobre a situação dos abrigos após a promulgação do ECA. Com o intuito de modificar essa situação, o Conselho Nacional dos Direitos da Criança e do Adolescente (Conanda) e o Departamento da Criança e do Adolescente (DCA) financiaram uma pesquisa, realizada no ano seguinte pelo Instituto de Pesquisa Econômica Aplicada (IPEA), para levantar dados sobre os abrigos do país.

É a partir desse contexto, que data do início de 2004, que se criam condições de possibilidade para que o Conanda (como órgão máximo em relação aos direitos da criança e do adolescente) eleja, como prioridade em seu planejamento estratégico, a promoção do direito de crianças e adolescentes à convivência familiar e comunitária. Assim,

${ }^{6}$ Dispõe sobre os princípios reguladores e as normas à proteção social, constituindo um mecanismo contra as formas de exclusão social. Inclui também as formas seletivas de distribuição e redistribuição de bens materiais e culturais que permitirão a sobrevivência e a integração, sob várias formas, na vida social (Cruz, 2009). ampliando a temática que se encontrava circunscrita à reordenação dos abrigos, tornou-se necessário redimensionar o grupo de trabalho, organizandose uma Comissão Intersetorial para a elaboração do PNCFC (Brasil, 2006). No mesmo ano, foi criado também o Plano Nacional de Assistência Social, que institui o Sistema Único da Assistência Social (Suas) - unificando as ações da Assistência Social, em território nacional, e operacionalizando as diretrizes da Loas.

Legislações que marcam a centralidade da família nas políticas públicas de proteção à infância e adolescência e que, por incidirem sobre determinada população, não são direcionadas ao governo de qualquer infância e adolescência, mas sim para uma específica: aquela atravessada e subjetivada pelo viés da violação de direitos, como nos mostram os dados do Levantamento Nacional de Abrigos para Crianças e Adolescentes. Crianças que são colocadas à margem em relação a uma infância constituída pelos parâmetros da normalidade.

Faz-se importante aqui remetermos à historicidade da instituição "adoção" em nosso país para compreendermos um pouco do processo político que possibilitou o rompimento com a noção de uma infância "menor" que, segundo Ayres, Carvalho e Silva (2002), ainda no século XX, se encontrava sem uma regulamentação específica quanto à adoção. 0 único dispositivo legal existente era o Código Civil, datado de 1917, que permaneceu até meados de 1979, ano em que foi reformulado o Código de Menores. Anteriormente, quem cuidava dessas questões era o Serviço de Assistência ao Menor (SAM).

A necessidade de novos dispositivos, com a participação do Estado, para as questões relativas às crianças abandonadas só será impulsionada com o aumento da pobreza e exclusão social durante a ditadura militar. Assim, durante os chamados "anos de chumbo" (em 1965) será criada a Fundação Nacional do Bem-Estar do Menor (Funabem) que, com o objetivo de reformular a Política Nacional do Bem-Estar do Menor (PNBEM), herda o acervo do SAM juntamente com suas arbitrariedades.

Nesse período é aprovada a lei 4.665 que complementa o instituto anterior da adoção, prática que passará a ser incentivada pelo Estado na tentativa de regular, com ajuda dos especialistas, as formas da infância de estar no mundo. A partir da reformulação

Psicol. Argum. 2013 jul./set., 32(76), 93-103 
da PNBEM aparece, então, a necessidade de fortalecer a família através de programas de atendimento e tratamento dos chamados menores marginalizados ${ }^{7}$. A Agência de Adoção é um exemplo de órgão que passa a operar com ações voltadas ao atendimento preventivo da população excluída, baseado no discurso da família como o melhor lugar para o desenvolvimento físico e psicológico da criança. 0 objetivo da Agência de Adoção era efetivar a PNBEM e minimizar a institucionalização prolongada, assim como atender à população compreendia como os menores em situação irregular iriam ser acolhidos pelas famílias (Ayres, Carvalho e Silva, 2002).

Conforme os autores, a perspectiva da família como o melhor lugar para a criança não dizia respeito a toda e qualquer organização familiar, pois havia um tipo de família ideal, marcada por lugares determinados, como o de pai e de mãe. E por entender que a responsabilidade pelo fracasso da família residia em si mesma, a PNBEM se preocupava apenas em colocar as crianças em lares substitutos, sem questionar a produção social do abandono e da exclusão. 0 próprio Código de Menores de 1979 - que regula a adoção sob duas formas: simples e plena - dispõe sobre esse modelo de família apropriado. Pela primeira forma, o adotado não se caracterizava totalmente como filho, o que acontecia somente mediante a adoção plena, concedida apenas para os casais com cinco anos de união legal e com mais de trinta anos de idade. Atributos que mostram a predileção e enaltecimento de uma única e ideal organização de família com possibilidade de passar por um processo de adoção plena. Assim, a instituição "adoção" que se instaura pela PNBEM, corroborada por especialistas como assistentes sociais, psicólogos, pedagogos, psiquiatras e advogados que desqualificavam outras formas de convivência familiar, seria "mais uma estratégia política do Estado para a minimização dos efeitos de uma política pública excludente do que uma possibilidade de atendimento a singularidades de crianças e famílias" (Ayres, Carvalho \& Silva, 2002, p. 135).

Segundo Fonseca (2009), a adoção, idealizada por juristas como uma imitação da natureza, era

\footnotetext{
7 Considerados assim, pelo "afastamento progressivo de um processo normal de desenvolvimento e promoção humana até a condição de abandono, exploração e conduta antissocial" (Bulcão, 2002, p. 131).
}

a única aposta, nos primeiros anos do ECA, que garantiria a saída das crianças e adolescentes dos abrigos. Na época, não se falava em famílias acolhedoras como uma medida que possibilitaria zelar por esses sujeitos e, ao mesmo tempo, manteria o vínculo com a família de origem. No entanto, o final dos anos 1990 veria uma mudança em relação à cultura que privilegiava a adoção, ao se perceber que ela não resolveria o problema das crianças e adolescentes abrigados na rede pública. Desse modo, a adoção como uma estratégia idealizada da garantia do direito à convivência familiar e comunitária passa a dar lugar a ações estratégicas que têm o objetivo de proteger o vínculo com a família de origem.

Uma passagem que nos permite visibilizar a família como instrumento importante do governo brasileiro. Logo, se a família está na base dos direitos atribuídos à infância e à adolescência, são esperadas deliberações políticas que busquem assegurar a efetivação do direito à convivência familiar e comunitária, assim como a promoção de uma mudança no paradigma do atendimento à criança e ao adolescente que seja consolidada por um documento como o PNCFC. Criado em 2006, ele registra a prioridade das ações do Governo Federal nesse campo, que teve como marco a criação, em 2004, da Comissão Intersetorial para Promoção, Defesa e Garantia do Direito de Crianças e Adolescentes à Convivência Familiar e Comunitária para a elaboração do referido plano (Brasil, 2006).

Como diretrizes operacionais da efetivação do referido direito, o PNCFC propõe a centralidade da família, o reconhecimento de sua autonomia e respeito à diversidade nas políticas públicas, a responsabilidade do Estado no fomento a políticas de apoio à família, o reconhecimento da autonomia de crianças e adolescentes em seu projeto de vida e a garantia de excepcionalidade em programas de acolhimento institucional e famílias acolhedoras. Além disso, propõe o reordenamento dos programas de acolhimento, a adoção centrada no interesse da criança e adolescente e o controle social das políticas públicas (Brasil, 2006).

A essas diretrizes políticas se soma a revisão da legislação que regulamenta a adoção no país, com a promulgação da Nova Lei de Adoção (Brasil, 2009). Uma mudança que pretende agilizar o processo de adoção e corroborar o caráter provisório das medidas de acolhimento institucional de crianças e 
adolescentes, garantindo a efetivação do direito à convivência familiar e comunitária.

Essa ênfase na centralidade da família nas políticas sociais do país permite articular algumas questões acerca da gestão econômica propostas por Foucault (2008). Questões que nos ajudam a pensar como os esforços governamentais de manter, ou reinserir a criança e o adolescente em uma família, não se relacionam apenas à garantia de um direito, mas, ao mesmo tempo, visam assegurar a potencialidade que o capital humano pode trazer ao desenvolvimento de uma nação.

Segundo as considerações do filósofo, a partir dos processos desencadeados pela teoria do capital humano, a análise econômica passa a se aventurar por campos até então inexplorados economicamente, o que possibilitará uma reinterpretação, "em termos estritamente econômicos [de] todo um campo que, até então, podia ser considerado, e era de fato considerado, não econômico" (Foucault, 2008, p. 302). Para o autor, com o surgimento do liberalismo, especificamente aquele concebido nos Estados Unidos, houve o desenvolvimento de mais do que uma simples organização política, pois o liberalismo norte-americano "é também um método de pensamento, uma grade de análise econômica e sociológica" (p. 301).

Se até o início do século XX (com Adam Smith) as análises econômicas clássicas operavam com o estudo dos mecanismos de produção, a crítica neoliberal propôs que essas análises fossem centradas na maneira como os recursos raros poderiam ser alocados para se obter determinados fins, "para a utilização eventual desses recursos raros, não um só fim ou fins que são cumulativos, mas fins entre os quais é preciso optar" (Foucault, 2008, p. 306). Análise que deve estudar "como os indivíduos fazem a alocação desses recursos raros para fins que são fins alternativos" (p. 306).

Desse modo, a economia passará a ser amplificada e estabelecida como uma ciência do comportamento humano que buscará elucidar as estratégias das atividades dos indivíduos, por meio de cálculos que poderão esclarecer quais recursos raros os indivíduos escolhem para chegar a um determinado fim (e não outro). Nesse processo, passam a operar os estudos genéticos que contribuem à formação do capital humano (composto de elementos inatos e adquiridos) e irão se debruçar sobre o investimento de competências-máquinas que irão constituir o futuro trabalhador. Assim, a preocupação com o desenvolvimento de capital humano se torna visível mediante investimentos como a educação - que vão além dos processos de escolarização e englobam questões como o cuidado e afeto dos pais com os filhos, os cuidados médicos e

toda uma análise ambiental, como dizem os americanos, da vida da criança, que vai poder ser calculada e, até certo ponto, quantificada, em todo caso, que vai poder ser medida em termos de possibilidades de investimento em capital humano (Foucault, 2008, p.316).

Desse modo, se é pelo governo da família que a criança poderá ser moldada, é também por meio dela que receberá um investimento crescente em capital humano. Nesse sentido, leis, documentos e políticas sociais funcionarão como braços de uma estratégia que tenta manter esse modo de conduzir a população para a manutenção e garantia do direito à convivência familiar, que, por sua vez, poderá potencializar o capital humano.

Portanto é interessante pensarmos sobre o que implica toda a movimentação política em torno da seguridade do direito à convivência familiar e comunitária ao longo da trajetória das políticas sociais do país. Se olharmos, ainda que brevemente, para os documentos que dispõem sobre a organização da Assistência Social no Brasil (como a Lei Orgânica de 1993 e a Política Nacional de Assistência Social), veremos como os vínculos familiares e comunitários são fundamentais para a garantia dos direitos, entre os quais se destaca a proteção à família (Brasil, 1993).

Diante dessa centralidade da família, com um operador das políticas públicas sociais, como conceber que algumas crianças e adolescentes permanecem fora do convívio familiar? Desse modo, quando nenhuma ação que busca a preservação dos vínculos familiares funciona ${ }^{8}$ para manter crianças e adolescentes em sua família de origem, ou quando nenhum convite à adoção (em território nacional) de determinadas crianças - que já não são mais bebês, nem são brancas - é aceito, há uma última esperança para esses sujeitos (e também um último

\footnotetext{
8 Como, por exemplo, o auxílio e o acompanhamento da família pelos operadores das políticas sociais.
}

Psicol. Argum. 2013 jul./set., 32(76), 93-103 
recurso previsto na hierarquia das ações que visam à garantia do direito à convivência familiar e comunitária): a adoção internacional. Como diz uma advogada durante a reportagem do Profissão Repórter que acompanha um processo de adoção internacional, quando alguém está em um abrigo e "já foi rejeitado por tudo (sic), por tua mãe, por tudo (sic), né, você não teve oportunidade na adoção nacional, aí vem a adoção internacional e diz assim: eu te quero do jeito que você é. Isso é maravilhoso".

Essa reportagem apresenta um casal italiano que irá adotar duas crianças brasileiras (duas meninas, irmãs, afrodescendentes e com faixa etária entre sete e nove anos ${ }^{9}$ ). 0 futuro pai, que depara com um grande número de crianças no abrigo onde se encontram as duas meninas, comenta: "se pudesse, levava todas as crianças para Itália". Essa fala - e sua escolha na edição para ser veiculada no programa - demarca e traz em si resquícios de um modo de olhar para a adoção (e, aqui, especialmente a adoção internacional) como se a única alternativa para a vida desses sujeitos, sua 'salvação' estivesse colocada na estratégia da adoção e, mais ainda, na adoção internacional.

Diante desse modo de pensar, que é atualizado na reportagem pela fala do italiano (que será o pai adotivo das meninas), o ato individual de adotar é colocado como uma ação que parece poder, sozinha, dar conta ou transcender toda uma problemática que se dispersa pelo tecido social - que diz respeito, por exemplo, às precárias condições de moradia, saúde, educação e trabalho de muitos brasileiros, e que está relacionada, direta ou indiretamente, ao fato de crianças e adolescentes necessitarem de uma medida de proteção como o serviço de acolhimento. Nada é mencionado sobre a produção social dessas condições nas reportagens. Tudo aparece como se a problemática em questão tivesse sempre um caráter individual, de determinada família que maltrata e/ou abandona (entre outros adjetivos semelhantes), sem relação com a produção dos modos de viver de determinado local e determinada época. Em função disso, perde-se de vista algo essencial, que é a razão da existência dos serviços de acolhimento. Crianças e adolescentes não se encontram nesses espaços porque estariam em completo abandono, mas porque necessitam deles como

9 Na reportagem não é especificada a idade das meninas. medida de proteção. Há uma série de fatores sociais e econômicos que levam tais sujeitos a viver parte de suas vidas nesses serviços, mas que ficam relegados à invisibilidade e, assim, passam a "não existir". E quando se mostram os motivos que levaram uma criança a viver (temporariamente) em um abrigo, frequentemente só se focam questões que acabam contribuindo para culpabilizar seus cuidadores.

Se, como mostramos anteriormente, é sobre a família que devem incidir as táticas que possibilitam uma arte de governar que conduz a conduta das populações, nada mais estratégico do que buscar integrar em uma família aqueles que, como as crianças e adolescentes abrigados, estão fora dela. 0 que faz com que tenhamos hoje estratégias, leis e planos que incitam a manutenção e uma vontade de família - que busca mobilizar os sujeitos à adoção, ao mesmo tempo em que garante às crianças e adolescentes o seu direito à convivência familiar e comunitária.

O que, muitas vezes, parece estar em jogo, lutando sempre por sua hegemonia, não diz respeito a pensar sobre que vida é possível para quem, por determinado tempo, se encontra fora da família. 0 que se sobrepõe é a problemática da afirmação da centralidade da família, que se coloca como um imperativo a ser atingido quase a qualquer custo. $\mathrm{Ou}$ a "baixo custo", como se pode depreender da iniciativa do Projeto de Lei (Almeida, 2011), em tramitação na Câmara dos Deputados, que prevê o dobro de dedução no imposto de renda, por dependente adotado, quando se tratar de crianças que sejam portadoras de doenças graves e/ou deficientes, afrodescendente, ou que estejam na faixa etária da chamada adoção tardia (com mais de dois anos de idade). Segundo o deputado federal, autor do projeto, "mais do que oferecer uma vantagem financeira ao contribuinte, queremos formalizar o reconhecimento do Estado àqueles que acolhem crianças e adolescentes normalmente rejeitados pela maioria dos pretendentes à adoção" (Projeto, 2011). Uma tática que pretende estimular a adoção como uma ação de solidariedade ${ }^{10}$, algo que lembra práticas que perpassam as relações de mercado, onde, para

\footnotetext{
${ }^{10}$ Conforme entrevista realizada com o Deputado Carlinhos Almeida, autor do Projeto de Lei. Recuperado em novembro de 2011, em http://www.youtube.com/ watch?v=y9Cj3ZUM3vk.
} 
além do desejo de quem adota, o importante é incitar a assumir (adquirir?) certas crianças/adolescentes através de incentivos financeiros. Isso porque, em uma racionalidade política na qual a família assume centralidade, tais sujeitos serão mais governáveis quando pertencerem a um grupo familiar. Somos convidados e seduzidos por uma vontade de família a partir de um modo de pensar que caracteriza nossas relações como econômicas, como se a escolha em adotar passasse simplesmente por uma relação de custo/benefício, em optar por certa "mercadoria" e não outra. 0 que preocupa não é apenas o fato de esse projeto ser ou não aprovado, mas a percepção de como vem se constituindo a prática social da adoção na atualidade. Se em outros tempos havia crianças ("menores") que não eram elegíveis à adoção por um evidente preconceito social, hoje estamos diante de crianças e adolescentes que se tornam elegíveis à adoção através de um desconto, constituindo-se mais uma vez pela via do que é menor, agora, um valor menor.

Oferecer um desconto no imposto de renda de quem adota é uma tática financeiramente mais viável do que manter crianças e adolescentes sob a proteção do Estado. Além do mais, é da família que se espera o melhor investimento na criança, o que, por sua vez, será para o Estado um investimento em capital humano. Assim, arriscamos perguntar: com o que ou quem o Estado estaria sendo solidário com semelhante projeto de lei?

Nessa perspectiva, é como se um incentivo financeiro pudesse dar conta de uma complexa problemática social que envolve não só a produção de infâncias e adolescências desiguais, mas dos preconceitos que forjam nosso modo de olhar para elas. Se, como pontuamos acima, em meados do século XIX e XX os esforços se destinavam a retirar os "menores" das ruas, a pergunta que inquieta agora é: será que continuamos a lidar com menores, hoje só diferentes porque nomeados de crianças em risco?

\section{Considerações finais: que práticas sociais queremos promover?}

Na busca em agilizar a efetivação do direito à convivência familiar e comunitária de crianças e adolescentes, faz-se importante atentar para os modos de pensar que acabamos produzindo nesse processo. Ao dispersar e atualizar discursos, como os que vemos através das reportagens veiculadas no programa Profissão Repórter e no Projeto de Lei que mencionamos, recolocamos a adoção como sendo uma espécie de 'salvação' da garantia do direito à convivência familiar e comunitária, algo que não problematiza as condições que exigem uma medida de proteção especial como o abrigamento ou, ainda, o que faz que um número tão grande de crianças e adolescentes com determinadas características permaneçam por mais tempo nos serviços de acolhimento do país.

Assegurar um direito aos sujeitos que dele foram privados é, sem sombra de dúvida, de suma importância às políticas de proteção à infância e adolescência de nosso país. No entanto, o que nos perguntamos é a que "custo" tentamos efetivá-lo quando se propõe um Projeto de Lei que visa mais a dedução no imposto de renda para quem desejar adotar crianças maiores de dois anos, afrodescendentes, portadores de deficiência ou doenças crônicas. Como se para a adoção de determinados "tipos" de crianças e adolescentes fosse necessário uma troca, certo ganho financeiro que beneficiaria tanto a família que adota quanto o Estado. Não se problematiza a produção social que faz que a maioria das crianças e adolescentes que necessitam de uma medida de proteção seja, por exemplo, afrodescendente ou, por que esse "tipo" de criança/adolescente não é preferível àqueles que desejam adotar, ainda que nosso país seja constituído por mestiços.

Outro ponto que nos chama muito atenção é a ênfase colocada sobre a criança nas reportagens veiculadas pelo Profissão Repórter, que parece demarcar uma espécie de invisibilidade do adolescente - e aqui pontuamos que não é por acaso que em diversas passagens, ao longo do texto, aparece apenas a expressão criança, pois muitas vezes apenas ela é mencionada. É como se não houvesse distinção entre o modo como as crianças e adolescentes vivem nessas situações, onde aos últimos caberia permanecer na mesma condição das crianças: vulneráveis e à espera. Ou, em uma hipótese mais dura ainda: seriam os adolescentes tomados como fatalmente "encalhados", sem esperança de mudança em sua situação de vida?

É preciso atentar para as práticas que desejamos promover e engendrar no âmbito social, afinal de contas, estamos falando de sujeitos que desejam e precisam ser desejados como tais - não crianças e adolescentes somente dignos de compaixão ou que

Psicol. Argum. 2013 jul./set., 32(76), 93-103 
podem entrar em uma espécie de "rol" de aquisições cotidianas (talvez revestida com a aura do mais correto politicamente), pautadas em relações inseridas na lógica do mercado.

\section{Referências}

Alencar, Helena. C. de. (2010). Quando a suíte vira novela: uso de estratégias narrativas ficcionais no telejornalismo. Anais do XXXIII Congresso Brasileiro de Ciências da Comunicação. Caxias do Sul, RS. (pp. 1-13). Recuperado em dezembro de 2011, em: http://www. intercom.org.br/papers/nacionais/2010/resumos/ R5-1889-1.pdf

Almeida, Carlinhos. (2011). Projeto de Lei $n^{\circ}$ 942, de 2011. Acrescenta o $\S 2^{\circ}$ ao art. $4^{\circ}$ da lei $n^{\circ}$ 9.250, de 26 de setembro de 1995, com o objetivo de dobrar o valor deduzido por dependente adotado ou sob guarda judicial, nas condições que especifica. Recuperado em dezembro de 2011, de http://www.camara.gov.br/proposicoesWeb/ fichadetramitacao?idProposicao $=497492$

Ayres, Lygia S. M.; Carvalho, Mauro da S. \& Silva, Mayalu M. (2002). Olhares sobre a instituição adoção: família e pobreza em questão. In Nascimento, M. L. (Org.). Pivetes: a produção de infâncias desiguais. (pp. 128143). Niterói: Intertexto; Rio de Janeiro: Oficina do Autor.

Brasil. (2009). Lei 12.010, de 3 de agosto de 2009. Dispõe sobre a adoção. Brasília/DF 2009. Recuperado em novembro de 2011 de http://www.planalto.gov.br/ ccivil_03/_Ato2007-2010/2009/Lei/L12010.htm

Brasil. (2006). Plano Nacional de Promoção, Proteção e Defesa do Direito de Crianças e Adolescentes à Convivência Familiar e Comunitária. Brasília/DF.

Brasil. (2004). O direito à convivência familiar e comunitária: os abrigos para crianças e adolescentes no Brasil. Brasília: Ipea/Conanda.

Brasil. (1993). Lei no 8.742/1993. Lei Orgânica da Assistência Social. Recuperado em agosto de 2012, em: http://www.ceas.pr.gov.br/arquivos/File/Lei_ Organica_da_Assistencia_Social.pdf.
Brasil. (1990). Lei 8.069. Estatuto da Criança e do Adolescente. Diário Oficial da República Federativa do Brasil. Brasília/DF, 13 julho.

Brasil. (1988). Constituição da República Federativa do Brasil. Brasília/DF: Senado, Recuperado em novembro de 2011 de http://www.planalto.gov.br/ccivil_03/constituicao/constitui\%C3\%A7ao.htm.

Cruz, Lílian R. da. (2009). Entre as legislações e a práxis do acolhimento para crianças e adolescentes. In: Mendes, J. M. R.; Prates, J. C. \& Aguinsky, G. B. (Org.). O Sistema Único de Assistência Social: entre a fundamentação e o desafio da implantação. (pp. 225-244). Porto Alegre: EDIPUCRS.

Bulcão, Irene. (2002). A produção de infâncias desiguais: uma viagem na gênese dos conceitos "criança" e "menor". In: Nascimento, M. L. (Org.). Pivetes: a produção de infâncias desiguais (pp. 61-73). Niterói: Intertexto; Rio de Janeiro: Oficina do Autor.

Fischer, Rosa M. (2002). 0 dispositivo pedagógico da mídia: modos de educar na (e pela) TV. Educação e pesquisa, jan/jun, v. 28, n. 00, pp. 151-162.

Fonseca, Claudia. (2009). Aventuras familiares: do acolhimento à adoção. In: Fonseca, C. e Schuch, P. (Orgs). Políticas de Proteção à infância: um olhar antropológico (pp. 273-294). Porto Alegre: Editora da UFRGS.

Foucault, Michel. (2009). Segurança, Território e População. São Paulo: Martins Fontes.

Foucault, Michel. (2008). O Nascimento da Biopolítica: curso dado no College de France (1978-1979). São Paulo: Martins Fontes.

Foucault, Michel. (2003). Poder e saber. In: Ditos $e$ Escritos IV: estratégia, poder-saber. (pp.223-240). Rio de Janeiro: Forense Universitária.

Foucault, Michel. (2004a). A arqueologia do saber. 7. ed. Rio de Janeiro: Forense Universitária.

Foucault, Michel. (2004b). A Governamentalidade. (pp. 277-293). Microfísica do Poder. 2. Graal. 
Gomes, Itânia. M. M. (2010). O Infotainment e a cultura televisiva. In: Freire Filho, j. (Org.) A TV em transição: tendências de programação no Brasil e no mundo. (pp. 195-212). Porto Alegre: Sulina.

Projeto estimula adoção dobrando dedução de Imposto de Renda. (2011). Recuperado em outubro de 2011, em: http://www.carlinhosalmeida.com.br/site/publish/noticias/article_3308.shtml\#.Tt4u0lYcVfy.

\section{Programa de Televisão:}

Profissão Repórter. (2010). Adoção. Rede Globo de Comunicações. Programa de TV. Recuperado em outubro de 2012, em: http://g1.globo.com/profissao-reporter/noticia/2010/08/profissao-reporter-mostra-rotina-da-maior-vara-de-adocao-do-pais.html.

Psicol. Argum. 2013 jul./set., 32(76), 93-103 